\title{
Comportamento de genótipos de mandioca quanto à podridão seca das raízes
}

Mauro Ferreira Bonfim Junior', Jeferson Thiago Zaia², Luiz Augusto Martins Peruch³, Augusto Carlos Pola ${ }^{4}$, Eduardo da Costa Nunes', Alexsander Luís Moreto'

Resumo - A podridão seca das raízes é uma das doenças mais destrutivas da mandioca (Manihot esculenta Crantz), podendo ocasionar perdas de produção de $30 \%$ a $100 \%$. Este trabalho teve por objetivo avaliar cultivares e clones avançados provenientes do programa de melhoramento genético de mandioca da Epagri, quanto à resistência à podridão seca causada por Fusarium solani. Uma suspensão de esporos de isolados de $F$. solani foi inoculada sobre discos de raízes de 21 genótipos de mandioca na concentração de $1,5 \times 10^{7}$ conídios. $\mathrm{mL}^{-1}$ em quatro experimentos. A severidade da doença foi avaliada por meio da porcentagem da área afetada pelo fungo. As manivas dos genótipos mais promissores nos testes de resistência foram selecionadas para testes com $F$. solani em casa de vegetação. O genótipo Luna foi o mais resistente dentre os avaliados e apresentou elevados valores de massa fresca de parte aérea e de raízes, tendo potencial para ser utilizado em áreas infestadas por $F$. solani e/ou como progenitor no melhoramento da cultura. Também os genótipos SC12-5035 e SC12-5029 apresentaram potencial para uso em programas de manejo integrado da doença.

Termos para indexação: Fusarium solani; F. oxysporum; resistência.

\section{Selection of cassava genotypes resistance to dry root rot}

Abstract - Dry root rot is the most damaging disease of cassava (Manihot esculenta Crantz). Yield reduction caused by the disease range from $30 \%$ to $100 \%$. This work aimed to assess cultivars and advanced clones from the cassava's genetic breeding program of Epagri for resistance to dry root rot caused by Fusarium solani. A suspension of $F$. solani spores was inoculated on root discs of 21 cassava genotypes, in a concentration of $1.5 \times 10^{7}$ conidia $\mathrm{mL}^{-1}$ in four experiments. The disease severity was assessed through the percentage area colonized by the fungus. Stems of the more promising genotypes in resistance tests were selected for tests with $F$. solani in greenhouse. The cultivar Luna has potential to be used in $F$. solani infested areas and/or as progenitor for the breeding program, as it was the more resistant and presented high values of mass of aerial part and roots among the genotypes tested. Also the genotypes SC12-5035 and SC12-5029 showed potential for use in integrated management of the disease.

Index terms: Fusarium solani; F. oxysporum; resistance.

\section{Introdução}

A podridão seca das raízes é uma das doenças mais destrutivas da mandioca (Manihot esculenta Crantz), podendo ocasionar perdas de produção de $30 \%$ a $100 \%$, com relatos de morte de até $30 \%$ das mudas sob condições naturais e de $100 \%$ de mudas inoculadas (POLTRONIERI et al., 2002). A doença é favorecida pela ocorrência de condições ambientais favoráveis, como solos ácidos e sujeitos a encharcamento (EMBRAPA,
2003). O seu agente causal, Fusarium spp., apresenta alta prevalência nas áreas de produção de mandioca ao redor do mundo. Bandyopadhyay et al. (2006) relataram que $30 \%$ das raízes tuberosas coletadas em Camarões afetadas por podridão radicular estavam infectadas por Fusarium spp. e que estas espécies representaram mais de $25 \%$ de todas as espécies encontradas.

Dentre as espécies relatadas, o complexo de espécies $F$. solani é o mais amplamente distribuído nas diferentes regiões produtoras mundiais, como por exemplo na Colômbia, Índia, Malásia, Nigéria e Nova Guiné (ADISA, 1983; SHAW, 1984; CHEARI et al., 2014; VILAS BOAS et al., 2017). O sintoma típico provocado pela colonização direta das raízes tuberosas por Fusarium é a podridão de consistência seca (OLIVEIRA et al., 2013). Fontes de resistência genética a Fusarium sp. tem sido encontradas em genótipos brasileiros adaptados à outras regiões do Brasil (OLIVEIRA et al., 2013).

Recebido em 1/7/2019. Aprovado para publicação em 11/11/2019.

Engenheiro-agrônomo, Dr., Epagri / Estação Experimental de Urussanga (EEUr), C.P. 49, 88840-000 Urussanga, SC, fone (48) 3403-1368, e-mail: maurojunior@ epagri.sc.gov.br; eduardon@epagri.sc.gov.br; alexsandermoreto@epagri.sc.gov.br

Estudante de Graduação, Instituto Federal Catarinense, Campus Santa Rosa do Sul, 88965-000, Santa Rosa do Sul, Santa Catarina, Brasil, e-mail: jefersonzaia10@ hotmail.com

Engenheiro-agrônomo, Dr., Epagri / Departamento de Marketing e Comunicação, 88840-000 Florianópolis, SC, fone (48) 3665-5175, e-mail: lamperuch@ hotmail.com

Engenheiro-agrônomo, M.Sc., Epagri / EEUr, e-mail: pola@epagri.sc.gov.br 
Levando-se em consideração a elevada produção de mandioca no estado de Santa Catarina, a disponibilidade de cultivares altamente produtivos da cultura e a elevada incidência da doença nas regiões produtoras, torna-se indispensável a caracterização de cultivares de mandioca visando à identificação de material resistente à Fusarium spp., evitando, assim, perdas de produção devido ao ataque do fungo.

Por esse motivo, o presente trabalho teve por objetivo avaliar cultivares/clones avançados provenientes do programa de melhoramento genético da mandioca da Epagri quanto à resistência à podridão seca causada por $F$. solani.

\section{Material e métodos}

\section{Identificação dos isolados de Fusarium}

Um levantamento de espécies de Fusarium em áreas comerciais de mandioca, na Região Sul de Santa Catarina, foi realizado com o objetivo de verificar a distribuição de Fusarium spp. na região.

Oito propriedades cujo produto final se destina a atender a indústria ou a mesa foram amostradas nos seguintes municípios: Sangão $\left(28^{\circ} 38^{\prime} 16^{\prime \prime}\right.$; $49^{\circ} 07^{\prime} 45^{\prime \prime}$ ) , São João do Sul $\left(29^{\circ} 13^{\prime}\right.$ $\left.24^{\prime \prime} \mathrm{S} ; 49^{\circ} 56^{\prime} 18^{\prime \prime} \mathrm{O}\right)$, Jaguaruna ( $28^{\circ} 36^{\prime}$ $54^{\prime \prime}$; $\left.49^{\circ} 01^{\prime} 32^{\prime \prime} \mathrm{O}\right)$, Sombrio (29 $06^{\prime}$ $14^{\prime \prime}$; $49^{\circ} 37^{\prime} 44^{\prime \prime} \mathrm{O}$ ) e Araranguá ( $28^{\circ}$ $\left.56^{\prime} 06^{\prime \prime} \mathrm{S} ; 49^{\circ} 29^{\prime} 09^{\prime \prime} \mathrm{O}\right)$. As amostras de raízes foram retiradas de plantas sintomáticas aleatoriamente na área ou dentro de reboleiras. Posteriormente, essas amostras foram levadas ao laboratório, onde se realizou o procedimento para isolamento de fungos em meio de cultura ágar-agua. Os isolados foram subcultivados em meio de cultura batatadextrose-ágar (BDA) e por meio de repicagens sucessivas foram mantidos no Laboratório de Fitopatologia da Estação Experimental de Urussanga.

A identificação morfológica dos isolados foi baseada na forma e no tamanho dos esporos (macro e microconídios), do corpo de frutificação assexual (conidióforo), e na coloração e pigmentação da colônia. A largura e o compri- mento de 50 macro e microconídios, escolhidos ao acaso, foram mensurados e identificados de acordo com a descrição de espécies de Fusarium (BURGESS et al., 1994), a qual permitiu somente a delimitação de putativos complexos de espécies do fungo.

\section{Testes de Resistência}

Quatro isolados pertencentes ao putativo Complexo de Espécies F. solani (FSSC - Fusarium solani Species Complex) foram selecionados e utilizados em mistura em quatro experimentos de resistência de genótipos em discos de raízes de mandioca provenientes do programa de melhoramento genético da Epagri. Foi incluída também a etnovariedade 'Mandim Branca', que é muito plantada no Litoral Sul de Santa Catarina (Tabela 1).

Por ocasião da inoculação, os isolados de $F$. solani foram repicados para meio de cultura BDA e mantidos em sala de crescimento à $28^{\circ} \mathrm{C}$ por 7-9 dias. Após esse período, adicionou-se água ultrapura (milia ${ }^{\circledR}$ ) autoclavada sobre a placa e promoveu-se a raspagem do meio de cultura para liberação dos esporos do fungo (micro e macroconídios). Em seguida, a suspensão de esporos foi filtrada em uma camada dupla de gaze, localizada sobre um funil acoplado em uma proveta. $O$ volume da suspensão resultante foi medido e a contagem dos esporos foi realizada em microscópio ótico (Objetiva de 10x) utilizando-se um hemocitômetro (Câmara de Neubauer). A concentração da suspensão esporos foi padronizada, por meio de diluição em $1,5 \times 10^{7}$ conídios $\mathrm{mL}^{-1}$.

Discos de raízes de cada genótipo com $3 \mathrm{~cm}$ de altura foram lavados, desinfestados com solução de $\mathrm{NaOCl}$ 0,5\% e secos sobre papel de filtro esterilizado. Esses discos foram inoculados com a suspensão de esporos em um ferimento com diâmetro de $0,6 \mathrm{~cm}$ produzido na região central do mesmo. No tratamen-

Tabela 1. Lista de genótipos utilizados por experimento (Exp.)

Table 1. List of genotypes used per experiment (Exp.)

\begin{tabular}{|c|c|c|c|c|c|}
\hline \multirow{2}{*}{ Genótipo } & \multicolumn{4}{|c|}{ Discos de Raízes } & \multirow{2}{*}{$\begin{array}{c}\text { Manivas } \\
\text { Exp. } 5 \text { e } \\
\text { Exp. } 6\end{array}$} \\
\hline & Exp. 1 & Exp. 2 & Exp. 3 & Exp. 4 & \\
\hline $\begin{array}{l}\text { Clone } \\
\text { Avançado }\end{array}$ & $\begin{array}{l}\text { SC12-5029 } \\
\text { SC11-2349 }\end{array}$ & $\begin{array}{l}\text { SC12-5035 } \\
\text { SC09-2165 } \\
\text { SC10-3077 } \\
\text { SC10-3094 } \\
\text { SC08-1054 } \\
\text { Sc08-1049 } \\
\text { SC09-2246 } \\
\text { SC09-2218 } \\
\text { SC08-1037 }\end{array}$ & $\begin{array}{l}\text { SC08-1037 } \\
\text { SC12-5035 } \\
\text { SC12-5029 }\end{array}$ & $\begin{array}{l}\text { SC12-5035 } \\
\text { SC12-5029 } \\
\text { SC13-6165 } \\
\text { sc08-1037 }\end{array}$ & $\begin{array}{l}\text { SC08-1037 } \\
\text { SC12-5029 } \\
\text { SC12-5035 }\end{array}$ \\
\hline Cultivar & $\begin{array}{l}\text { 'Sambaqui' } \\
\text { 'Luna' } \\
\text { 'Guapo' } \\
\text { 'Ajubá' } \\
\text { 'Uirapuru' } \\
\text { 'Sempre } \\
\text { Pronto' }\end{array}$ & - & $\begin{array}{l}\text { 'Sambaqui' } \\
\text { 'Luna' } \\
\text { 'Guapo' } \\
\text { 'Jaguaruna' } \\
\text { 'Ajubá' } \\
\text { 'Sangão' } \\
\text { 'Uirapuru' }\end{array}$ & $\begin{array}{l}\text { 'Sambaqui' } \\
\text { 'Luna' } \\
\text { 'Guapo' } \\
\text { 'Jaguaruna' } \\
\text { 'Ajubá' } \\
\text { 'Sangão' } \\
\text { 'Uirapuru' }\end{array}$ & $\begin{array}{l}\text { 'Sambaqui' } \\
\text { 'Luna' } \\
\text { 'Guapo' } \\
\text { 'Ajubá' } \\
\text { 'Uirapuru' }\end{array}$ \\
\hline Etnovariedade & - & $\begin{array}{c}\text { Mandim } \\
\text { Branca }\end{array}$ & - & - & - \\
\hline
\end{tabular}


to controle aplicou-se somente água ultrapura esterilizada. As unidades experimentais foram colocadas em bandejas de plástico, cobertas com filme PVC e mantidas à uma temperatura de $26^{\circ} \mathrm{C}$.

Os sintomas localizados a $2 \mathrm{~mm}$ abaixo da superfície foram medidos aos dez dias após a inoculação (DAl). A área lesionada $\left(\mathrm{cm}^{2}\right)$ foi obtida por meio do software ImageTool (University of Texas Health Science Center, San Antonio, TX, USA) (OLIVEIRA et al., 2013), sendo a severidade da doença expressa em porcentagem da área total dos discos de raízes.

O delineamento experimental utilizado para todos os experimentos foi o inteiramente casualizado com seis repetições. As médias de severidade da doença nos genótipos inoculados foram submetidas a análise de variância e comparadas pelo teste de Scott-Knott a $5 \%$ de significância.

\section{Experimentos com manivas}

Os genótipos considerados mais promissores nos testes de resistência foram selecionados e utilizados em dois experimentos de inoculação de manivas em casa de vegetação (Tabela 1 ).

Manivas com $20 \mathrm{~cm}$ de compri- mento, diâmetro medular de no máximo $50 \%$ do diâmetro total da estaca e quatro gemas foram pré-selecionadas a partir de plantas assintomáticas com 8-10 meses de idade e submetidas a desinfestação superficial com hipoclorito a $0,5 \%$ por 3 minutos. Após a desinfestação o material foi imerso em uma suspensão contendo $1,5 \times 10^{7}$ conídios $\mathrm{mL}^{-1}$ por uma hora. Em seguida, as manivas foram plantadas em sacos plásticos, contendo solo esterilizado, de acordo com a metodologia descrita por Santiago et al. (2018). Manivas testemunhas foram imersas em água ultrapura.

As variáveis avaliadas foram o número de manivas-semente brotadas, incidência de murcha a cada 7 dias, massa fresca de raízes de absorção (g) (MFR) e de parte aérea (g) (MFPA) aos 45 DAl.

$O$ delineamento experimental foi $O$ inteiramente casualizado em esquema fatorial $(8 \times 2 \times 10)$ : oito genótipos, dois procedimentos de inoculação (inoculado/não inoculado) e dez repetições. As médias de MFR e MFPA de cada tratamento inoculado, em cada experimento e de forma conjunta de ambos experimentos foram submetidas a análise de variância e agrupadas pelo teste de Scott-Knott a 5\% de significância. A comparação de médias de MFR e MFPA entre um mesmo genótipo inoculado e não inoculado foi feita pelo Teste $t$ a $5 \%$ de significância.

Análise de correlação de Pearson foi realizada entre área lesionada dos discos de raízes (\%) e as variáveis MFR e MFPA do experimento com manivas.

\section{Resultados e discussão}

\section{Identificação dos isolados de Fusarium}

De acordo com as características culturais e morfológicas, em todos os cinco municípios amostrados, foram identificados isolados putativos de FSSC (VILAS BOAS et al. 2017; O'DONNELL et al., 2013). No município de São João do Sul também foi identificado um isolado putativo de FOSC (VILAS BOAS et al. 2017; O'DONNELL et al., 2013). Os isolados putativos de FSSC caracterizaramse por apresentar micélio cotonoso de coloração branca (superfície superior da colônia), pigmentação branca amarelada à branca amarronzada (superfície inferior da colônia) em meio de cultura BDA, macro e microconídios, monofiálides longas e não ramificadas. Já o isolado putativo de FOSC caracterizouse por apresentar micélio cotonoso de coloração branca-violeta e pigmentação

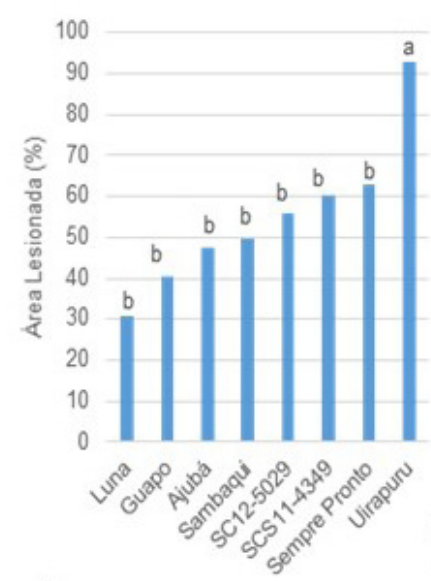

A

Figura 1. Severidade da área radicular interna afetada (em porcentagem) de $F$. solani em discos de raízes de mandioca. A - Experimento 1. B - Experimento 2. C - Experimento 3. D - Experimento 4. (Colunas seguidas por letras minúsculas iguais pertencem ao mesmo grupo de genótipos de acordo com o Teste de Scott-Knot à $5 \%$ de significância)

Figure 1. Severity of the inside root area affected of F. solani in root discs of cassava. A - Experiment 1. B - Experiment 2. C - Experiment 3. $D$ - Experiment 4. (Columns followed by the same lowercase letters belong to the same group of genotypes according Scott-Knot Test $5 \%$ of significance) 
violeta em meio de cultura BDA, monofiálides curtas com microconídios em falsa-cabeça (SUMMERELL et al., 2003).

Os microconídios de FSSC variaram de ovais à elipsoides, retos à curvados, apresentaram de 0 a 1 septo e mediram de 4-30 $\mu \mathrm{m}$ de comprimento e 2-7 $\mu \mathrm{m}$ de largura. Os macroconídios foram escassos em meio de cultura BDA, fusoides, apresentaram de 2 a 3 septos; a célula apical mostrou-se pequena, arredondada e às vezes em forma de gancho; e células basais dentadas (BURGESS et al., 1994).

Os microconídios de FOSC foram produzidos abundantemente em monofiálides curtas em falsa-cabeças, não septados, variaram de ovais a elipsoides, retos a curvados, e mediram de

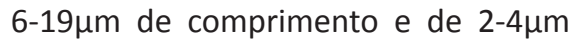
de largura (MUI-YUN, 2003; BURGESS et al., 1994). Clamidósporos não foram observados em FSSC nem em FOSC.

\section{Testes de resistência}

Levando-se em consideração todos os experimentos de avaliação de resistência em discos de raízes, foi observado que o cultivar Luna não apresentou variação de comportamento, sendo sempre agrupado como resistente. Os clones avançados SC12-5035 e SC125029 apresentaram comportamento variado, ora comportando-se como resistentes, ora como suscetíveis (Figura 1).

Uma hipótese a ser levantada em face do comportamento instável desses clones é o fato de haver alguma diferença no nível nutricional dos dois clones por ocasião da produção das raízes. Tanto os macros como os micronutrientes influenciam na síntese de metabólitos de secundários, como as fitoalexinas e os glicosídeos cianogênicos, que possuem efeito na resistência de plantas a doenças. Além disso, quando a planta está em desequilíbrio nutricional o acú- mulo de substâncias orgânicas de baixo peso molecular favorece o desenvolvimento de patógenos (MARSCHNER, 1995; YAMADA, 2004).

\section{Experimentos com manivas}

O número de manivas-semente brotadas foi de $100 \%$ aos 7 DAl e plantas com sintoma de murcha não foram observadas durante o período experimental nos experimentos 5 e 6 . Tais resultados diferem dos de Santiago et al. (2018), cujos cultivares testados, Fécula Branca e Olho Junto, apresentaram sintomas de murcha e amarelecimento, chegando à morte aos 60 DAI.

No experimento 5 os genótipos SC12-5035, SC12-5029 e 'Luna' foram os que apresentaram os maiores valores de MFR quando inoculados com $F$. solani. No entanto, o cultivar Luna foi o que mais sofreu redução da variável, em comparação com a testemunha não
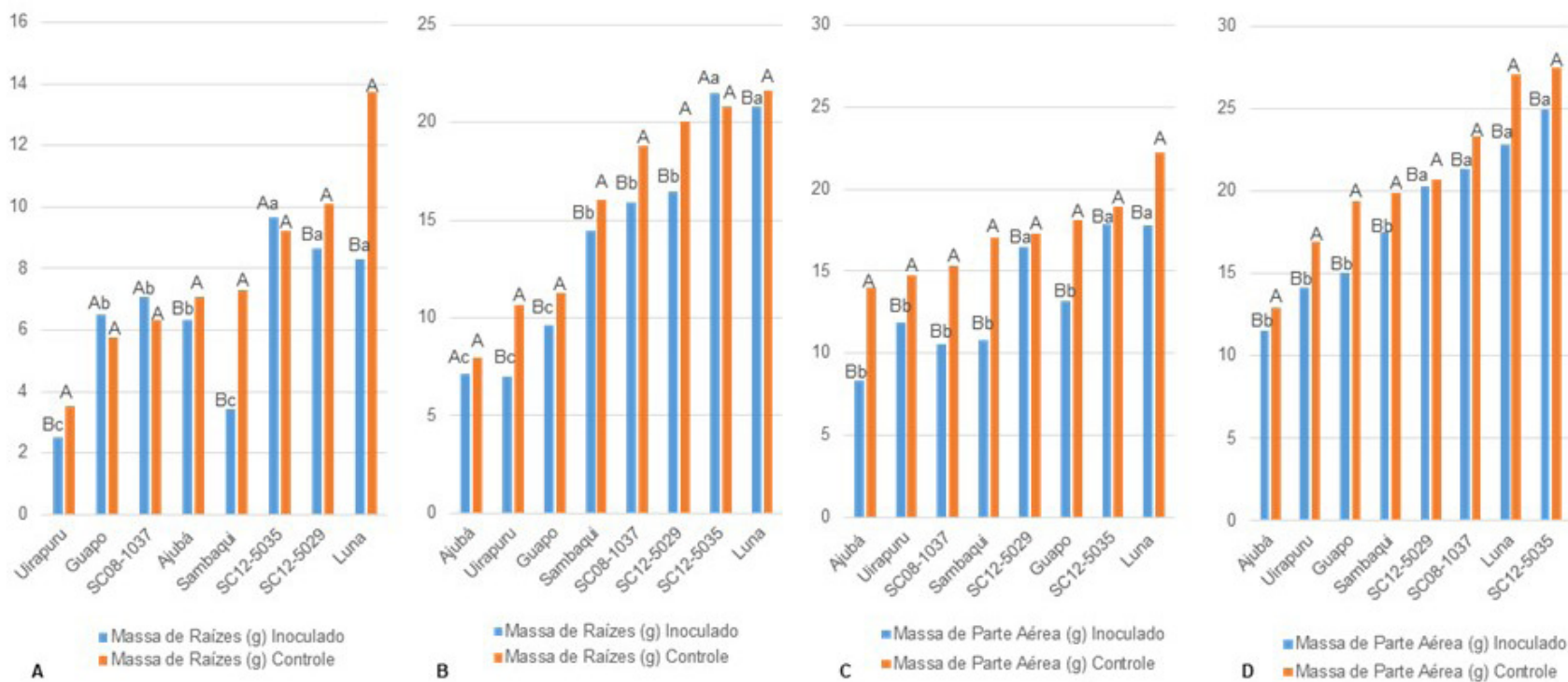

Figura 2. Massa de raízes de genótipos inoculados e não inoculados com F. solani. A - Massa de raízes (Experimento 5). B - Massa de raízes (Experimento 6). C - Massa de parte aérea (Experimento 5). D - Massa de parte aérea (Experimento 6). (Colunas seguidas por letras maiúsculas iguais não diferem entre o mesmo genótipo inoculado e não inoculado de acordo com o Teste t a 5\% de significância; Colunas seguidas por letras minúsculas iguais pertencem ao mesmo grupo de genótipos inoculados de acordo com o Teste de Scott-Knot a 5\% de significância)

Figure 2. Root weight of cassava genotypes inoculated and non-inoculated with F. solani. A - Experiment 5. B - Experiment 6. (Columns followed by the same uppercase letters are not different between the same genotype inoculated and non-inoculated according to $t$ Test $5 \%$ of significance; Columns followed by the same lowercase letters belong to the same group of genotypes according Scott-Knot Test 5\% of significance) 
inoculada. No experimento 6 não houve diferença significativa de MFR entre os genótipos SC12-5035 e 'Ajubá' e os seus respectivos controles não inoculados. Quando os genótipos inoculados foram comparados entre si, novamente SC125035 e 'Luna' se destacaram, apresentando os maiores valores de MFR (Figura 2).

Levando-se em consideração a variável MFPA, no experimento 5 , todos os genótipos sofreram redução significativa quando comparados com as suas respectivas testemunhas não inoculadas. Quando os genótipos inoculados foram comparados entre si, 'Luna', SC12-5035 e SC12-5029 apresentaram os maiores valores de MFPA, diferindo estatisticamente dos demais. No experimento 6 , todos os genótipos diferiram estatisticamente da testemunha não inoculada quanto à MFPA. Os genótipos SC125029, SC08-1037, 'Luna' e SC12-5035 apresentaram os maiores valores de MFPA, diferindo estatisticamente dos demais, quando os genótipos inoculados foram comparados entre si (Figura 2). Experimento semelhante realizado por Santiago et al. (2018) mostrou redução significativa de massa de parte aérea, massa de raízes e volume de raízes dos cultivares Fécula Branca e Olho Junto inoculados em relação aos não inoculados com $F$. solani.

A análise estatística conjunta dos experimentos 5 e 6 mostrou que os genótipos 'Luna' e SC12-5035 agruparam-se como os melhores genótipos com relação à MFR e MFPA. O genótipo SC125029 agrupou-se junto aos melhores genótipos apenas quanto à MFPA (Figura 3).

De acordo com os resultados desses experimentos nota-se que os genótipos 'Luna' e SC12-5035 se destacaram quanto à MFR e MFPA em todos os casos. O clone avançado SC12-5029 também se destacou, exceto quando foi avaliada a MFR no experimento 6 .

Vilas Boas et al. (2017) assinalaram a necessidade de avaliação de genótipos de mandioca quanto a diferentes espécies causadoras de podridão de forma individual, pois o comportamento dos patógenos no campo pode variar de
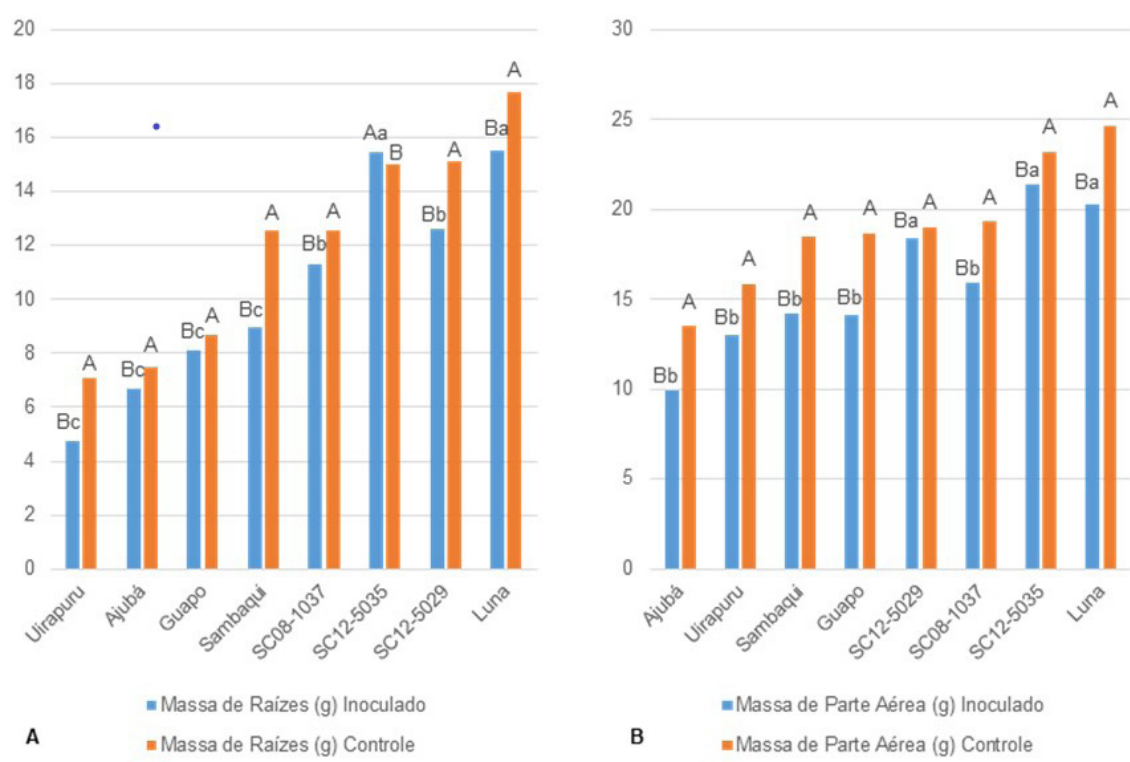

Figura 3. Massa de raízes (A) e massa de parte aérea (B) de genótipos inoculados e não inoculados com F. solani (Análise conjunta dos Experimentos 5 e 6). (Colunas seguidas por letras maiúsculas iguais não diferem entre o mesmo genótipo inoculado e não inoculado de acordo com o Teste t a 5\% de significância; Colunas seguidas por letras minúsculas iguais pertencem ao mesmo grupo de genótipos inoculados de acordo com o Teste de Scott-Knot a $5 \%$ de significância)

Figure 3. Root weight $(A)$ and Mass of aerial part (B) of cassava genotypes inoculated and non-inoculated with F. solani (Simultaneous analysis of Experiments 5 and 6). (Columns followed by the same uppercase letters are not different between the same genotype inoculated and non-inoculated according to t Test 5\% of significance; Columns followed by the same lowercase letters belong to the same group of genotypes according Scott-Knot Test $5 \%$ of significance)

acordo com a localidade. A dificuldade de aplicação do controle químico de patógenos radiculares leva à necessidade de adoção de medidas de controle integradas como a rotação de culturas, o plantio direto e o uso de cultivares resistentes. Dessa maneira, os genótipos que apresentaram menor severidade da podridão seca neste trabalho, como os cultivares Luna (Experimentos 1, 3 e 4) e os clones avançados SC12-5035 (Experimentos 2 e 4) e SC12-5029 (Experimentos 1 e 4) podem ser utilizados no manejo integrado dessa doença da mandioca.

Oliveira et al. (2013) observaram

Tabela 2. Correlação de Pearson entre área lesionada dos discos de raízes (AL), massa fresca de parte aérea (MFPA) e massa fresca de raízes (MFR)

Table 2. Pearson's correlation between lesioned area (AL), top fresh weight (MFPA) and root fresh weight (MFR)

\begin{tabular}{lccc}
\hline Variáveis & AL & MFPA & MFR \\
\hline AL & 1.00000000 & $-0.2195273^{\text {ns1 }}$ & $-0.2737807^{\text {ns2 }}$ \\
MFPA & $-0.2195273^{\text {ns1 }}$ & 1.00000000 & 0.9043579 \\
MFR & $-0.2737807^{\text {ns2 }}$ & 0.9043579 & 1.00000000
\end{tabular}

${ }^{1}$ Correlação entre área lesionada e massa fresca de parte aérea: $\mathrm{gl}=46$, $\mathrm{p}$-value $=0.1338$

${ }^{2}$ Correlação entre área lesionada e massa fresca de raízes: $\mathrm{gl}=46$, $\mathrm{p}$-value $=0.05971$

Ns: Não significativo a $5 \%$ de probabilidade. 
que nenhum dos acessos de germoplasma testados apresentou resistência completa. Vilas Boas et al. (2016) testaram a severidade de Fusarium spp. em 697 acessos de mandioca e também observaram ausência de resistência completa, sugerindo que a herança resistência seja quantitativa. De acordo com Onyeka et al. (2005), a identificação de genótipos resistentes pode ser feita pela inoculação de ramas, fatias de raízes ou raízes inteiras, tal qual foi aplicado no presente trabalho. Vale lembrar que é provável que os diferentes tecidos tenham mecanismos distintos na resistência à podridão por Fusarium (SANTIAGO et al., 2018). Ao se fazer o teste de correlação de Pearson (Tabela 2), observou-se uma correlação negativa entre a área lesionada dos discos de raízes e MFR/MFPA, entretanto esta correlação foi baixa e não significativa. Isso indica uma possível diferença de resistência entre tecidos das raízes de absorção e as raízes de acúmulo de substâncias de reserva.

Por este motivo é importante continuar estudando os mecanismos de resistência à doença e efetuar o screening de novos cultivares a fim de disponibilizar material resistente aos produtores.

\section{Conclusão}

O cultivar Luna foi o mais resistente à podridão seca dentre os genótipos do programa de melhoramento genético da Epagri avaliados e tem potencial para ser utilizado em áreas infestadas por $F$. solani.

Os clones avançados SC12-5029 e SC12-5035 são promissores para uso no manejo da doença nessas áreas.

\section{Agradecimentos}

Os autores agradecem os extensionistas rurais da Epagri Diego Adílio da Silva, Emerson Evald, Homero Rock Bosch Júnior, Natalício Marcon Nandi e Sandoval Miguel Ferreira; e o extensionista da Prefeitura Municipal de Sangão, Marco Remor pelo apoio na condução aos locais de coleta de amostras de raízes doentes.

\section{Referências}

ADISA, V.A. Surface mycoflora of Manihot esculenta and $M$. utilissima tubers in Nigeria. Indian Phytopathology, Nova Déli, v.36, p.533-538, 1983.

BANDYOPADHYAY, R.; MWANGI, M.; AIGBE, S. O.; LESLIE, J. F. Fusarium species from the cassava root rot complex in West Africa. Phytopathology, St. Paul, v.96, n.6, p.673676, 2006.

BURGESS, L.W.; SUMMERELL, B.A.; BULLOCK, S.; GOTT, K.P.; BACKHOUSE, D. Laboratory manual for Fusarium research. Fusarium Research Laboratory. 3 ed. Sidney: Department of Crop Sciences, University of Sidney, 1994. 132p.

CHEARI, K.; SALLEH, B.; ZAKARIA, L. Fusarium virguliforme, a soybean sudden death syndrome fungus in Malaysian soil. Australasian Plant Disease Notes, v.9, p.1-7, 2014

EMBRAPA. Cultivo da mandioca para a região do cerrado. Sistemas de Produção. Jan. 2003. Disponível em: https://sistemasdeproducao.cnptia.embrapa.br/FontesHTML/ Mandioca/mandioca_cerrados/doencas. htm. Acesso em: 22 mar. 2017.

MARSCHNER, H. Mineral Nutrition of Higher Plants. 2. ed. San Diego: Academic Press, 1995. 889p.

MUI-YUN, W. (2003) Fusarium oxysporum f. sp. lycopersici (Sacc.) W.C. Snyder and H.N. Hans. PP728 Soilborne Plant Pathogen Class Project. NC State University. Disponível em: https://projects.ncsu.edu/cals/course/ pp728/Fusarium/Fusarium_oxysporum. htm. Acesso em: 21 fev. 2018.

O'DONNELL, K.; ROONEY, A.P.;PROCTOR, R.H.; BROWN, D.W.; MCCORMICK, S.P.; WARD, T.J.; FRANDSEN, R.J.N.; LYSOE, E.; REHNER, S.A.; AOKI, T.; ROBERT, V.A.R.G.; CROUS, P.W.; GROENEWALD, J.Z.; KANG, S.; GEISER, D.M.Phylogenetic analyses of RPB1 and RPB2 support a middle Cretaceous origin for a clade comprising all agriculturally and medically important fusaria. Fungal Genetics and Biology, v.52, p.20-31, 2013.

OLIVEIRA, E.J.; HOHENFELD, C.S.; SANTOS, V.S.; HADDAD, F. Resistance to Fusarium dry root rot disease in cassava accessions. Pesquisa Agropecuária Brasileira, Brasília, v.48, n.10, p.1414-1417, 2013.

ONYEKA, T.J., DIXON, A.G.O.; EKPO, E.J.A. Assessment of laboratory methods for evaluating cassava genotypes for resistance to root rot disease. Mycopathologia, v.159, p.461, 2005. DOI:http://dx.doi. org/10.1007/s11046-004-6156-z.

POLTRONIERI, L.S.; TRINDADE, D.R.; ALBUQUERQUE, F.C.; DUARTE, M.L.R.; CARDOSO, S.S. Incidência de Fusarium solani em mandioca no estado do Pará. Fitopatologia Brasileira, v.27, n.5, p.544, 2002.

SANTIAGO, C.H.; SANTANA, M.P.; CAIRO JUNIOR, L.R.; OLIVEIRA, S.A.S.; OLIVEIRA, E.J. Methodologies for selecting cassava with resistance to dry and black root rot under controlled conditions. Bragantia, v.77, n.3, p.440-451, 2018.

SHAW, D.E. Microorganisms in Papua New Guinea. Research Bulletin of the Department of Primary Industries Port Moresby, v.3, p.1-344, 1984.

SUMMERELL, B.A.; SALLEH, B.; LESLIE, J.F. A utilitarian approach to Fusarium identification. Plant Disease, St. Paul, v.87, n.2, p.117128, 2003.

VILAS BOAS, S.A.; HOHENFELD, C.S.; de OLIVEIRA, S.A.S.; SANTOS, V.S.; OLIVEIRA, E.J. Sources of resistance to cassava root rot caused by Fusarium spp.: a genotypic approach. Euphytica, Dordrecht, v. 209, p. 209-237, 2016. DOI: http:// dx.doiorg/10.1007/s10681-016-1676-4

VILAS BOAS, S.A.; OLIVEIRA, S.A.S; BRAGANÇA, C.A.D.; RAMOS, J.B.; OLIVEIRA, E.J. Survey of fungi associated with cassava root rot from different producing regions in Brazil. Scientia Agricola, Piracicaba, v.74, n.1, p.60-67, 2017.

YAMADA, T. Resistência de plantas às pragas e doenças: pode ser afetada pelo manejo da cultura? Informações Agronômicas, $n^{\circ} 108$, p.1-7, 2004. Disponível em: <https://www. npct.com.br/publication/ia-brasil.nsf/44F0 5CF57F94E09483257AA200597351/\$File/ Page1-7-108.pdf> Acesso em: 06 ago. 2019 . 